\title{
A Maternidade como Enigma: Atenas, as Luzes e Freud
}

GRACIELA QUINTANA GOMEZ

\section{RESUMO}

Este trabalho examina a questão da maternidade, a partir de uma abordagem histórica das construções discursivas dominantes na Grécia Clássica e nas Luzes, e da análise de determinados textos de Freud. O objetivo principal é tentar demonstrar o peso de uma tradição patriarcal, que remonta à Antigüidade sobre a representação fálica da maternidade de Freud (embora ele também abra outras linhas interpretativas alternativas), sustentada em três pilares fundamentais: o monismo fálico, o essencialismo no entendimento da questão da diferença entre os sexos e a idéia de que as mães têm os filhos sozinhas, sem intervenção do pai.

Palavras-chave: Maternidade; representação fálica; história; psicanálise. 
Neste trabalho, analiso o discurso dominante sobre a maternidade na Atenas democrática do século $\mathrm{V}$ a.C. e a sociedade pré e pós-Revolução Francesa, com o objetivo de identificar e medir o peso que alguns de seus traços mais característicos tiveram no pensamento freudiano a propósito desse tema. Embora sejam enormes as diferenças que separam ambas sociedades, houve nelas uma mesma necessidade de pensar a maternidade como uma questão-chave do processo de organização social. A seguir, é esse saber sistemático produzido social e historicamente, e não a "realidade" das mulheres-mães nas respectivas situações, que me proponho a analisar.

Enquanto na Grécia foi construída uma teoria sobre a reprodução que excluía a mulher da maternidade, na sociedade moderna se fabricou uma ideologia maternal que buscava no corpo, na anatomia, na biologia e na fisiologia femininas, signos para justificar a idéia de que a mulher havia nascido para ser mãe e só mãe. A diferença - quase diríamos radical entre essas duas concepções é evidente: no primeiro caso, as mulheres eram despojadas da maternidade; no segundo, elas eram fixadas na maternidade, apelando à natureza e a argumentos essencialistas. Mas isso não significa que, na prática, nos dois casos, as mulheres não tivessem que ser mães para terem algum lugar de reconhecimento na sociedade e, por outro lado, que tais discursos não sejam produto de uma mesma matriz de pensamento patriarcal (apesar de que, como veremos mais adiante, na sociedade moderna este era muito mais sutil e menos implacável que na Grécia). Analisemos, em primeiro lugar, o modo como a maternidade era pensada na sociedade grega, mas também a diferença entre os sexos e a sexualidade. Essas duas dimensões intimamente ligadas ao tema da maternidade.

\section{Os Gregos e as Mães}

$\mathrm{Na}$ tradição do pensamento ocidental, Atenas designa o momento fundador da democracia, mas também de um modo de organização patriarcal da sociedade que, em relação a reprodução: primeiro, despoja as mulheres da maternidade, e; em seguida, reconhece sua participação, embora destacando que esta é só secundária. Loraux sustenta esta idéia, e a analisa através de alguns mitos importantes na criação da democracia ateniense, bem como do pensamento filosófico de Aristóteles, que constitui, na sua opinião, o pensamento dominante sobre reprodução no imaginário ateniense (Loraux, 1990).

Comecemos pelo mito de autoctonia. Este mito confirma o desejo de excluir a mulher da maternidade porque diz que Erichtonios, o primeiro homem, o primeiro cidadão ateniense, nasceu diretamente da Terra (Géia), 
sobre a qual caiu o sêmem de um deus, e não do corpo de uma mulher. Por haver nascido da Terra, Erichtonios se transformou no autóctone, no fundador da cidade de Atenas, que recebeu esse nome em homenagem à deusa Atena, que o acolheu recém-nascido dos braços de Géia. Com a deusa Atena, o desejo grego de excluir a mulher da maternidade adquire ainda mais força, mas se expressa de um modo diferente, através de sua virgindade, e porque ela nasceu da cabeça de seu pai Zeus e não do corpo de uma mulher. Essa deusa permite acreditar que se nasce de um, fora do encontro sexuado e que, em conseqüência, já que se nasce de um, melhor que seja do pai e não da mãe, como se pensava antes da instauração do patriarcado. Em relação à maternidade de Zeus, podemos dizer que esta completa o quadro da ideologia patriarcal em sua expressão mais radical, pois, como observa Sissa, o grande deus se apropria da maternidade, no sentido pleno da palavra, ao "comer", literalmente, a deusa Métis, grávida de Atena (Sissa, 1993).

Em última instância, os gregos não só queriam negar a maternidade, mas também a própria existência das mulheres. É isso o que demonstra outro mito - o mito de Pandora - relatado pelo poeta Hesíodo, que nos fala de um tempo em que as mulheres não existiam e os homens viviam felizes sem elas. Pandora, a primeira mulher, surge como um artefato, fabricada por Zeus com terra e água com a ajuda do deus Hefaístos. Com ela se inicia para os gregos o conceito de "raça das mulheres", ou seja, a idéia da mulher como pertencendo a um grupo separado, a uma tribo, a uma raça maldita que será excluída da polis grega e do direito de cidadania. Pandora surge sozinha diante de uma comunidade já constituída de homens, demonstrando, desse modo, que ela não é mãe da humanidade, mas apenas mãe das mulheres (Loraux, 1990).

Todos esses mitos demonstram, de diferentes modos, que os gregos preferiam excluir a mulher da reprodução: o mito de autoctonia, porque diz que os filhos nascem da Terra (Géia) e não de uma mulher; a deusa Atena, porque figura como a filha do pai, que nasceu do cérebro de Zeus e não teve mãe; o mito de Pandora, porque diz que ela nasce num tempo posterior, quando já existia uma comunidade de homens que ninguém sabe como nasceram, mas que estavam aí, vivendo felizes e sem problemas graças à ausência de mulheres. Isso no nível do mito, do desejo, do sonho, porque a realidade mostrava que essa denegação do feminino não poderia ser levada até as últimas conseqüências, pois, de fato, a cidade precisava delas para se reproduzir. E já que é preciso reconhecer-lhes um papel na reprodução - e 
o corpo feminino é uma expressão clara de sua participação nela -, melhor então, impor-lhes o discurso do deus Apolo, que reduz ao máximo sua intervenção.

É isto o que expressa a tragédia $A$ Orestéia, do poeta trágico Ésquilo, que se inscreve como mito fundador do pai e que marca a instauração do patriarcado no Ocidente, ou seja, a substituição da evidência da filiação materna pela certeza da filiação masculina (Freud, 1939; Laqueur, 1990; Loraux, 1990). O cenário desta tragédia é uma guerra real que houve entre gregos e troianos e os protagonistas, uma família real, cujo pai era Agamenon, sua esposa Clitemnestre, e os três filhos - Ifigênia, Electra e Orestes. Agamenon sacrifica sua filha Ifigênia, oferecendo-a em sacrifício para poder ganhar uma batalha decisiva. Para vingar a morte de sua filha, Clitemnestre o mata; Orestes, por sua vez, para vingar a morte de seu pai, mata sua mãe. Ao ser acusado pelo Corifeu de matar a mulher que o trouxe ao mundo e o amamentou, Orestes nega qualquer laço com ela. É nesse momento que intervém o deus Apolo em defesa de Orestes, proclamando que o único pai verdadeiro, quem realmente engendra, é o macho e não a fêmea (Sissa, 1993).

Deixemos agora os mitos e passemos para a filosofia. Aristóteles transforma as palavras do deus Apolo, na defesa a Orestes, numa linguagem supostamente mais racional que os mitos. Ele foi o pensador grego a assumir a posição mais radical contra a mulher e queria, como homem de seu tempo, eliminar a crença na partenogênese feminina e substituí-la pela partenogênese masculina. Com ele, a idéia representada nas palavras do deus Apolo começará a adquirir forma de teoria, cujo objetivo será explicar, através dos critérios que naquela época eram considerados "científicos", que o verdadeiro gerador era o homem e que a mulher não era mais que um corpo onde o homem depositava o germe para que ela o alimentasse e o conservasse.

Em suma, o que esse mito e o pensamento de Aristóteles revelam é que, com a origem do patriarcado, surge uma concepção sobre reprodução radicalmente oposta àquela que vigorou durante o longo período que se estende desde o Paleolítico até a Idade de Ferro (ou seja, até o século V a.C., quando se instaura a democracia no Ocidente). Nessa época anterior, como observa Badinter (1986), existia o culto à grande e fértil deusa-mãe que havia engendrado o universo sozinha e se pensava também que as mulheres, do mesmo modo que as deusas, tinham os filhos sozinhas, sem intervenção do homem, através da inserção do feto em seus corpos depois de um contato com algum objeto ou animal do cosmos. Essa concepção implicava atribuir 
todo o poder ao sexo feminino em detrimento do masculino? A partir do livro de Bachofen, $O$ matriarcado, surgiram diferentes interpretações sobre o tema. Mas o que nos interessa sublinhar é que houve um tempo anterior ao patriarcado - cuja data é incerta, mas que está inscrito na história - no qual as mulheres eram valorizadas a partir da maternidade e não eram excluídas dessa experiência, como o foram mais tarde, desde a instauração da democracia em Atenas até fins do século XVII, quando começou pela primeira vez a ser questionada de um modo mais eficiente a idéia de que o único verdadeiro gerador era o pai e não a mãe (Laqueur, 1990).

Voltando ao pensamento dominante sobre reprodução no imaginário ateniense, é importante enfatizar que, por trás dessa concepção sobre reprodução construída por Aristóteles (a partir, sem dúvida, de uma representação que já se encontrava presente nos mitos), havia a necessidade de definir o feminino como inferior, incompleto e imperfeito em relação ao masculino. A partir da idéia de que existe uma diferença biológica originária entre os sexos que associa o masculino com o calor e a perfeição, e o feminino com o frio e a imperfeição, o filósofo afirmava que o homem, por ter uma constituição quente, era capaz de gerar no outro porque podia cozinhar o sangue para que este se transformasse em esperma, mas que a fêmea, por ser fria, não podia realizar essa operação de metamorfose. Isso significava que a participação da mulher na geração era só secundária, limitando-se a alimentar o germe com seu sangue e a oferecer o corpo como lugar onde o homem deposita o germe (Sissa, 1993). Nesta mesma linha de pensamento, Laqueur (1990) observa que desde a Antigüidade se constrói a idéia de uma inferioridade biológica feminina para justificar não só seu papel secundário na reprodução, mas também o lugar inferior que ela ocupava na sociedade: Aristóteles utilizava o termo akuros para descrever ao mesmo tempo a ausência de legitimidade política e a incapacidade biológica da mulher, ou seja, para provar que ela era, tanto política como biologicamente, semelhante a uma criança e uma versão impotente do homem. Em outras palavras, que a potência biológica do esperma para engendrar uma vida nova era o aspecto corporal microcósmico do potencial racional do cidadão e de seu direito de governar.

Queremos salientar que desde aquelas épocas remotas, os "homens" (pois até o século XIX eram só os homens que pensavam e escreviam sobre essas questões) buscavam signos no corpo feminino para justificar o lugar que se queria atribuir à mulher na sociedade, realizando desse modo a mesma operação de pensamento que será realizada na modernidade pelos 
médicos e filósofos dos séculos XVIII e XIX. Em ambos os casos, o discurso dominante se apropria da maternidade, poder-se-ia dizer, para construir um pensamento adequado ao que a sociedade necessita para seu bom funcionamento: ele (o homem) é o sujeito das representações, cujo objeto é a mulher. Só que no primeiro caso, edifica-se uma teoria sobre a reprodução que reduz ao máximo a intervenção feminina e, no segundo caso, inventase a idéia de que a mulher havia sido talhada pela natureza para ser mãe. O peso do sistema patriarcal, sem dúvida, é mais forte no primeiro caso, quando se quer desvincular a mulher da maternidade e se associa, de um modo radical, o feminino a uma categoria inferior, como o fazia de um modo sistemático Aristóteles. Mas isso não significa que ele não continue presente na sociedade moderna, embora de um modo muito mais sutil, menos explícito e implacável do que no caso da sociedade grega.

Assim, com Aristóteles, se inaugura um modo de pensar a diferença entre os sexos em termos de uma dicotomia hierarquizante que, partindo de um sistema de categorias binárias de pares de opostos (calor/frio, masculino/ feminino), associa-se de modo inexplicável o calor a um valor positivo e ao masculino; e o frio, a um valor negativo e ao feminino. Obviamente, existe a diferença anatômica e fisiológica entre os sexos, mas o problema é que a partir dela constroem-se classificações hierárquicas para fundamentar uma desigualdade social entre os sexos que se pretende impor de maneira universal (Héritier, 1996). Esta questão será retomada no próximo tópico, ao se analisar o discurso dominante da sociedade pré e pós-Revolução Francesa, onde, do mesmo modo que na sociedade ateniense, os homens (filósofos e médicos) também pensaram as questões da diferença entre os sexos e a maternidade, construindo um saber sistemático e universalizante, que marcará mais tarde, em outro contexto histórico, o pensamento freudiano (ao menos em alguns pontos centrais).

\section{O Iluminismo e a Ideologia Maternal}

A partir de finais do século XVIII, e especialmente no século XIX, começa a ser construído um novo discurso que invoca argumentos essencialistas para fundamentar a idéia de que a mulher havia sido talhada pela natureza para ser mãe e permanecer no lar como guardiã da moral e dos bons costumes. Embora esse novo discurso se apresentasse igualmente como um sistema homogêneo de pensamento, que aspirava a uniformizar, invocava agora a biologia, a anatomia e a natureza, entendidas todas elas de um modo diferente de como eram entendidas antes, com o objetivo de 
provar que toda mulher havia nascido para ser mãe. A emergência desse novo modelo responde a um processo histórico de mudança social, sumamente complexo e contraditório, desencadeado pelas profundas transformações que acompanharam a expansão do capitalismo e a consolidação do Estado-Nação moderno, e entre as quais, privilegiaremos duas - uma, que poderíamos denominar de "revolução científica"; e a outra, de "revolução político-ideológica”. Comecemos pela primeira.

a) Descobertas científicas importantes ocorridas num espaço de tempo bastante curto - durante o século XVII - possibilitaram um modo novo de entender três questões fundamentais: a reprodução, a diferença entre os sexos e a relação entre prazer e reprodução. O historiador Laqueur analisa cada uma delas e sua própria história - ou seja, como eram explicadas essas questões antes e depois do século XVII -, destacando que essas descobertas não podem ser consideradas separadamente, mas como parte de um processo mais amplo, que inclui uma nova visão do mundo (que implica também um novo modo de entender o corpo, não mais através de um pensamento metafísico), vinculada ao que se convencionou chamar de "revolução científica". Vejamos, então, como foram entendidas no decorrer do tempo estas três questões.

1. Pode a mulher procriar? A crença na potência do homem para gerar e a conseqüente destituição da capacidade de gerar da mulher perduraram para além da democracia ateniense, durante muitos séculos. Como vimos, ela era decorrência direta de uma afirmação político-cultural do sistema patriarcal, isto é, um exercício de preservação do pai sobre a reivindicação sensorialmente evidente da mãe. As longas discussões que começaram na Antigüidade e continuaram até o século XVII sobre a semente feminina - para saber se a mulher participava ou não da obra genésica sempre chegavam às mesmas conclusões: ou ela não tinha uma semente (os partidários do filósofo Aristóteles); ou ela tinha, mas esta era mais fraca que a do homem (os partidários do médico Galeno, que viveu no século II, mas cujo pensamento perdurou até fins do século XVII). Portanto, nos dois casos era mantida a potência e a capacidade do homem gerar, e anulada ou limitada a participação feminina. Essa teoria começou a ser questionada de modo mais contundente só no século XVII, quando Harvey descobriu o óvulo, mas foi eliminada de maneira definitiva no século XIX, quando Oskar Hertwig descobriu que, para haver fecundação, é necessário o "encontro" efetivo do ovo com o espermatozóide (Laqueur, 1990, p. 197). A nova teoria sobre reprodução que passa a reconhecer a participação dos dois sexos 
consegue, assim, eliminar um pensamento tributário da lógica patriarcal mais intransigente que, originada em Atenas, havia destituído as mulheres durante séculos de sua capacidade de procriar. Isto sem dúvida merece ser destacado, embora o que chama verdadeiramente a atenção é que essa descoberta tenha acontecido apenas no século XIX. Como explicar a persistência desse pensamento durante tanto tempo? Segundo Laqueur (1990, p. 80), ela responde ao temor de que predomine a teoria contrária, aquela que atribui a procriação só às mulheres, devido a dificuldade de provar a paternidade e a evidência da maternidade. Por isso, se inventam princípios "abstratos" para provar a paternidade e se afirma que esta é superior justamente porque precisa de um trabalho de pensamento para ser reconhecida, à diferença da maternidade, que aparece através da percepção dos sentidos, tal como afirma Freud em Moisés e a religião monoteísta.

2. A mulher deve sentir prazer para procriar? Embora até agora nada tenhamos dito sobre a relação entre prazer e reprodução, é preciso sublinhar que os gregos foram muito menos opressivos com a sexualidade que os modernos (Brown, 1992). Aristóteles não falava sobre o prazer feminino porque seu principal objetivo era substituir a crença na partenogênese feminina pela idéia de que o verdadeiro gerador era o macho, mas para os médicos hipocráticos prazer e mulher estavam tão intimamente ligados que pensavam que se ela não tinha orgasmo não podia procriar. Esta opinião dos médicos gregos, que mais tarde foi confirmada e mais bem elaborada por Galeno, prevaleceu durante séculos, até o surgimento da ciência moderna: ambos os sexos sentiam prazer na relação sexual, e esse prazer era considerado necessário para a reprodução, pois sem ele não haveria possibilidade de ter uma geração frutuosa (Laqueur, 1999, p. 67). Até fins do século XVII, portanto, o prazer sexual feminino era considerado como fonte de uma vida nova, ou seja, como um elemento indispensável para que a espécie pudesse conservar-se; que, em algumas épocas (na Idade Média), tenha sido reprimido é um fato que em todo caso não invalida sua relação com a concepção (Chauí, 1984; Sennett, 1997). Esta situação se modifica radicalmente a partir do fim do século XVII, quando o "apetite da carne" feminino - presente desde os gregos mas que, à diferença do homem medieval, não os ameaçava - desapareceu por obra e graça da nova ciência médica e da maneira como ela foi utilizada para impor o novo modelo de mulher: quando se descobriu que o prazer não era necessário para procriar (que as mulheres podiam engravidar quando estavam dormindo, por exemplo), o orgasmo deixou de ser visto como signo de uma feliz geração, para ser relegado aos confins 
da fisiologia e começar a operar como indicador biológico da diferença entre os sexos (Laqueur, 1990, p. 16). A descoberta de que o prazer feminino não é necessário para conceber serviu, portanto, de base para construir a idéia de que, biologicamente, a mulher era passiva sexualmente, que sua única vocação era a maternidade, e que sua sexualidade só era satisfeita com o parto e a vida doméstica (Knibiehler, 1994). Tal construção, como veremos mais adiante, corresponde perfeitamente ao modelo de mulher que queriam construir os homens da Revolução e, por outro lado, explica porque nenhum autor se preocupou em questionar o orgasmo masculino quando, de fato, a descoberta de que o prazer não era necessário para conceber, alcançava tanto homens como mulheres. Em relação à construção da idéia de uma passividade sexual feminina inata, é importante destacar que sem dúvida ela teria sido inviável no pensamento anterior, onde eliminar o prazer implicava questionar algo que desde sempre foi inquestionável: a conservação da espécie. Abordemos agora o próximo ponto, intimamente ligado a este: a utilização da anatomia e da biologia para construir a idéia de que existe uma diferença radical, de essência, de natureza, entre os sexos, que está na base da construção de uma "maneira de ser" feminina ou masculina.

3. A mulher - gênero diferente ou sexo diferente? Na Antigüidade, havia uma diferença de gênero (o que atualmente chamamos "gênero"), ou uma diferença de sexo entre homens e mulheres? Quando e como foi construída a idéia de uma diferença entre os sexos apoiada numa argumentação essencialista ou naturalista? Laqueur demonstra que em Aristóteles ele falava em termos de uma diferença biológica entre os sexos, mas já se encontram os gérmens de uma concepção que surgiu com Galeno (no século II) e se manteve dominante, apesar das críticas e polêmicas - até fins do século XVII, segundo a qual a diferença entre homens e mulheres era de grau e não de sexo. Essa teoria define os sexos em função de critérios binários (quente/frio) e segundo o telos da perfeição, ou seja, segundo a idéia de que o mais imperfeito sempre tende ao mais perfeito. Conforme esse critério, havia uma "diferença de grau" entre os sexos e não biológica nem anatômica, apoiada na idéia de que os órgãos genitais femininos eram iguais aos masculinos, só que revertidos para dentro. Desde a Antigüidade, vigorou essa representação, na qual se pensava que a mulher podia transformar-se em homem se o calor aumentasse (porque, nesse caso, seus órgãos genitais poderiam descer), mas não o inverso, pois o homem, quente, era a própria encarnação da perfeição. Todos compartilhavam o mesmo sexo, o que não significa que não houvesse uma diferença de gênero que 
justificava a atribuição de diferenças sociais, jurídicas e políticas bem definidas para homens e mulheres.

Com a descoberta de uma diferença anatômica entre os sexos (fins do século XVII), a questão dos sexos passou a ser abordada como uma questão puramente biológica, a partir da qual seria possível afirmar a viva voz que homens e mulheres eram diferentes, ou seja, que a mulher jamais poderia transformar-se em homem porque a natureza a fez diferente. Com esta nova construção, resolvem-se alguns problemas e criam-se outros: a mulher surge como "outra" - poderíamos dizer, se pensarmos que seus órgãos reprodutivos adquirem uma especificidade que antes (durante mais de dois mil anos) não tinham porque eram vistos como iguais aos masculinos, só que revertidos para dentro. Mas o problema é que, a partir da descoberta de uma diferença anatômica entre os sexos, seu corpo (geralmente seus órgãos de reprodução) começou a ser utilizado para construir a idéia de que o ser feminino, por natureza, tinha sido feito para ser mãe e permanecer no espaço privado. Portanto, as duas construções - ou seja, tanto o modelo do sexo único como o modelo dos dois sexos - devem ser vistas como produtos sociopolíticoculturais, signos de uma ordem social hierarquizada que, no modelo antigo, serve ao interesse patriarcal de reivindicar o pai e não a evidência sensorial da filiação feminina. E no modelo moderno, serve ao interesse - também patriarcal, embora menos rígido que o anterior - de construir uma diferença de essência entre os sexos, apoiada numa nova concepção da biologia que justifique a exclusão da mulher do domínio público e sua fixação no papel maternal, como guardiã da moral e dos bons costumes.

Fraisse, autora que também estuda a construção do novo modelo no período anterior e posterior à Revolução Francesa, destaca que a ideologia maternal que começa a ser construída no século XVIII e se impõe sobretudo no século XIX deve ser vista dentro de um contexto político mais amplo. Que significa isso? Que para compreender como foi construído o novo modelo de mulher, temos que considerar também o peso que teve a outra revolução que mencionamos anteriormente - a "revolução político-ideológica", que acompanhou a Revolução Francesa.

b) No fim do Antigo Regime, as mulheres estavam nas ruas, nas manifestações políticas, no espaço público, nos salões literários, fazendo parte da esfera pública em gestação e dela participando sob as mais diversas formas, organizadas ou não. Para alguns pensadores, cujas idéias tiveram um papel fundamental na época, como Rousseau, por exemplo, elas estavam adquirindo um poder excessivo e eram a causa principal da decadência dos 
costumes, da moral e da sociedade; para outros autores, menos delicados com as mulheres que Rousseau, elas eram as "responsáveis pelo mal", as "culpadas do mal" (Fraisse, 1998, p. 173).

Os médicos e filósofos da época começaram a discursar e a escrever no quadro do imaginário da Revolução, buscando encontrar signos de uma diferença corporal no corpo feminino que possa ditar as diferenças sociais e jurídicas do novo Código. A partir da idéia de que existe um paralelo entre o físico e o moral, foram construindo uma "maneira de ser" feminina, ancorada numa diferença e até numa oposição de essência e natureza entre os sexos que fosse capaz de justificar o novo lugar que se queria dar às mulheres. De responsáveis pelo mal, elas se viram transformadas, no dia seguinte à Revolução Francesa, em "responsáveis pelo bem" e representantes da moralidade que a nova sociedade queria restabelecer na nova sociedade. Mas esta não foi uma tarefa fácil para os pensadores, porque se tratava de encontrar signos no corpo feminino que demonstrassem que ela não estava apta para a vida pública e política (ou porque era sensível e emotiva demais, ou porque era menos inteligente), mas que, ao mesmo tempo, também demonstrassem que ela era racional e responsável o suficiente como para poder ser a representante da moral e dos bons costumes, ou seja, alguém capaz de cumprir com eficiência seu dever de boa mãe republicana que educa seus filhos para serem bons cidadãos.

Assim, o corpo feminino serviu para criar uma "maneira de ser" feminina que pretendia refletir, como um espelho, uma significação supostamente inscrita na sua anatomia e fisiologia:

1) o mito da "mulher truncada" começou a ser substituído por outro mito, o mito da "mulher-útero", um estranho órgão que a mulher tem dentro de si, que ao mesmo tempo em que lhe permite não ser mais vista como a cópia defeituosa do macho, por outro lado, a condena a ser sua prisioneira, pois cria uma nova tipologia onde o feminino é identificado com maternidade ou com doença, quando não consegue cumprir de modo eficiente o papel que a sábia natureza lhe traçou (Knibiehler, 1994; Berriot-Salvadore, 1994);

2) o tamanho do cérebro feminino serviu para resolver definitivamente um problema: se o cérebro da mulher e seu sistema nervoso eram tão sensíveis (porque o útero, supostamente o órgão mais importante do corpo feminino, transmitia-lhe sua própria sensibilidade) e, portanto, tão pouco aptos para a vida pública e política, por que as mulheres renunciariam tão facilmente às paixões e aos prazeres sexuais? Essa 
pergunta-problema que se colocavam os médicos encontrou finalmente uma resposta no tamanho do cérebro: porque seu cérebro era menor! Desse modo, a idéia de uma passividade sexual feminina teria encontrado um argumento sólido, inquestionável, porque ancorado na própria anatomia, para convencer as mulheres de que elas "nasceram" para ser mães e permanecerem em seus lares, educando seus filhos e moderando a paixão (sexual, se entende, porque no resto o sexo masculino era identificado à razão) de seus homens (Laqueur, 1990, p. 237). Apesar de que muitas mulheres não renunciavam totalmente ao $\mathrm{sexo}^{2}$, e de que muitas adoeciam por terem que renunciar involuntariamente, a essa realidade, que contradizia as novas verdades da ciência sobre a passividade sexual feminina, e não dissuadia os médicos de continuarem se esforçando para provar que essa passividade estava inscrita na sua anatomia. Nesse sentido, a repressão da sexualidade que começou a ser construída a partir das Luzes foi, em grande medida, pior que as anteriores, porque invocava a "natureza" e a "essência" femininas para cortar o mal pela raiz, pode-se dizer; ou seja, para convencer as mulheres de que a "biologia" as havia feito passivas sexualmente e aptas somente para a maternidade e o privado. Michelet (1798-1874) foi um fiel representante desta ideologia da maternidade e do espaço privado, que fixa a sexualidade feminina nas intensidades do parto e da amamentação. Ele considerava a maternidade como um instinto com o qual toda mulher nascia e, ao mesmo tempo, como uma compensação por causa da recusa ao prazer sexual que acompanhava o ideal de casamento. Idealizava-a, mas apenas em sua dimensão dolorosa, como se não houvesse lugar para o prazer, como se o erotismo materno fosse identificado só com dor e sofrimento. Também Balzac retrata essa ideologia da rainha do lar da burguesia e da classe média através de Renée, o personagem principal de sua obra Mémoires de deux jeunes mariés: casada com um homem gentil, Renée deseja a maternidade para poder viver o erotismo e o prazer que não vive com seu marido e vivencia a experiência da amamentação com uma sensação semelhante ao orgasmo (Badinter, 1980). Em minha opinião, o problema não é ligar maternidade e erotismo, ainda menos quando se trata de um erotismo que integra também a dimensão do prazer, como no caso da personagem de Balzac, que incorpora esta dimensão ausente em Michelet. O problema é querer limitar a sexualidade feminina só à maternidade, porque isso contribui para forjar a idéia de uma sexualidade materna devoradora, que é preciso, sobretudo e antes de nada, 
limitar, controlar. Antes de abordar esse tema, que em realidade é introduzido pela própria psicanálise, gostaria de destacar dois pontos em relação ao discurso iluminista.

Em primeiro lugar, a presença de um paradoxo importante inerente à democracia moderna, que permite entender por que o século XIX é o século das mães, mas não o século da submissão das mulheres: o princípio de "igualdade" de todos perante a lei que traz a Revolução, apesar de provocar a exclusão das mulheres da vida pública (através, como disse, da utilização da descoberta da nova ciência para construir uma "diferença" de essência entre os sexos que justifique tal exclusão), traz em seu seio a possibilidade de inclusão das mulheres através da luta pelo reconhecimento da igualdade dos direitos cívicos, políticos e sociais. Que significa isto? Que embora tenha estabelecido poderosas normas coletivas orientadas a modelar condutas, o novo discurso não foi completamente eficaz e, assim, a representação totalizante que se quis impor começou progressivamente a se desfazer diante das lutas e resistências impulsionadas pela multiplicidade de identidades femininas que começaram a aflorar - de trabalhadora, mãe, emancipada, politizada (Fraisse \& Perrot, 1994).

Em segundo lugar, que a partir das Luzes e do próprio processo da Revolução, a visão da mulher como impotente e incapaz, mantida durante séculos, espelhando e afirmando de modo explícito e sem ambigüidades a cultura patriarcal em sua versão mais rigorosa, teve que ser modificada, pois era impossível falar do sexo feminino de um modo que contrariasse a idéia de que ele contribuía para o processo civilizatório como representante da moral e dos bons costumes. O pensamento patriarcal não podia ser tão inflexível como o dos gregos porque, para os modernos, a mulher tinha uma responsabilidade cívica, uma cidadania moral, para que a espécie humana se tornasse mais perfeita (Fraisse, 1998). Mas como e em que medida essas matrizes discursivas de Atenas e do Iluminismo estão presentes no pensamento de Freud sobre a maternidade?

\section{Freud e a Maternidade}

A psicanálise surgiu no século XIX, como ruptura radical com o pensamento racionalista dominante da época, a partir das idéias de inconsciente, de pulsão e de sexualidade infantil. Mas quando pensava a questão da maternidade, é necessário reconhecer nela não só a forte influência do pensamento que dominava na época, mas também de uma tradição que, originada muito tempo atrás, na própria instauração do patriarcado, se arras- 
tava ao longo dos séculos. Refletirei sobre esta hipótese, privilegiando três questões importantes presentes em Freud, que permeiam e orientam a representação que ele constrói sobre a maternidade, ao menos em uma de suas versões - na versão fálica. Trata-se, em primeiro lugar, do monismo fálico, ou seja, de um modo de pensamento que remonta aos gregos, onde o feminino é definido a partir do referencial masculino e sempre como inferior a ele. Em segundo lugar, do essencialismo, ao qual Freud acabou recorrendo quando construiu uma teoria sobre a diferença sexual, mostrando que, como homem de sua época, ele não conseguia desvincular-se da idéia de que "toda" mulher nasceu para ser mãe. Finalmente, de uma crença muito antiga que remonta a um tempo inclusive anterior ao patriarcado - a idéia de que as mães têm os filhos sozinhas, sem a participação do homem.

\section{$O$ monismo fálico}

A partir das idéias principais que acabo de desenvolver, apoiada no pensamento dominante na sociedade ateniense e na sociedade moderna, é possível afirmar uma certa correspondência entre três imagens de mulher e três momentos históricos diversos também. Num primeiro momento, poder-se-ia dizer que a mulher não existia (no mito de autoctonia e no mito de Pandora); num segundo momento, ela ganha o direito à existência, mas a uma existência considerada imperfeita e inferior em relação ao homem (em Aristóteles e mais tarde em Galeno); e, finalmente, que ela existia apenas como mãe. Esta caracterização do feminino já estava presente na Grécia (onde, como vimos, apesar de a procriação ser vista como obra do macho, a mulher só era reconhecida através da maternidade), mas, de fato, ela corresponde de um modo muito mais forte à representação sobre a mulher construída a partir das Luzes, pois é, nesse momento, que, pela primeira vez, são invocados argumentos biológicos para tentar transformar a maternidade num imperativo unificador do "sexo feminino".

Essa referência geral à história permite que nos aproximemos da construção teórica freudiana sobre o desenvolvimento psicossexual da criança e reconheçamos nela - salvando obviamente as distâncias e singularidades de cada discurso - um movimento análogo constituído também por três momentos diferentes. Em relação ao primeiro momento - quando descreve a primeira etapa dessa evolução e diz que a sexualidade da menina é masculina e que o clitóris é um pênis, embora de tamanho menor -, pode-se afirmar que para Freud a mulher não existe, no sentido em que o sexo originário é o sexo masculino (Freud, 1905; 1908). No segundo momento, logo depois da 
descoberta da diferença entre os sexos, o feminino aparece pela primeira vez, mas é definido a partir da idéia de falta e, nesse sentido, pode-se dizer que a mulher existe, sim, mas apenas como um menos-macho, ou seja, enquanto castrada (Freud, 1923; 1925): a primazia do falo, presente no momento anterior através da idéia de um sexo e uma sexualidade masculinos, únicos e comuns aos dois sexos, assume aqui uma nova forma, pois há um masculino, mas não um feminino, já que a oposição não é masculino/feminino, mas fálico/castrado. Como observa Sissa (1993), neste sentido, Freud não diz nada novo, limita-se a confirmar a velha concepção de Aristóteles e Galeno, que definia a mulher a partir do referencial masculino e sempre como imperfeita em relação a ele. Por último, quando constrói finalmente uma teoria sobre a diferença entre os sexos, diríamos que a mulher existe, mas apenas como mãe, pois, segundo Freud (1924; 1925; 1933), a menina com disposição bissexual só conseguirá tornar-se uma verdadeira mulher a partir da maternidade, segundo a conhecida equação pênis=filho, único modo de substituir (já que renunciar é impossível) o desejo de ter um pênis pelo desejo de ter um filho. Neste terceiro momento, o paralelismo homem-mulher cede lugar à diferença, sim, mas a uma diferença que se anula ao mesmo tempo em que é formulada, na medida em que o filho é visto como substituto do pênis, o que nos leva a concluir que, mesmo quando Freud enuncia a diferença entre os sexos, continua existindo apenas um sexo como referente - o masculino ${ }^{3}$.

Essas três concepções de mulher são três versões diferentes do monismo fálico freudiano. Isto parece evidente nos dois primeiros casos, quando se considera a mulher inexistente e quando ela é definida a partir da idéia de falta - como cópia imperfeita e incompleta do homem -, mas não no terceiro caso, quando é identificada com maternidade. Com efeito, conferir um pênis à mãe através da equivalência pênis=filho é uma construção que, em princípio, pareceria questionar o monismo fálico, ao menos parcialmente, pois apesar de o feminino continuar sendo definido a partir do masculino, ele deixa de ser visto como inferior. No entanto, considero importante dizer e insistir em que esta representação da maternidade também é uma versão do monismo fálico - certamente mais sutil que as anteriores, que exige um esforço para ser compreendida - porque, como veremos mais adiante, ela acaba reenviando inevitavelmente a uma imagem inteiramente negativizada da maternidade e, em última instância, da própria mulher. 


\section{A Teoria Freudiana sobre Diferença entre os Sexos e o Essencialismo das Luzes}

Freud problematizou o essencialismo vigente na época para definir o masculino e o feminino, através da introdução de alguns elementos importantes, como a idéia de uma bissexualidade comum aos dois sexos que impedia afirmar que existe um masculino e um feminino puros (Freud, 1925); e a idéia do feminino visto como destino e não como origem, quando dizia que a mulher não nasce mulher, mas deve percorrer um longo caminho para "tornar-se" mulher (Freud, 1924). No entanto, quando construiu uma teoria sobre a diferença entre os sexos, acabou invocando o argumento da anatomia (da castração) para explicar a transformação da menina-castrada em mulher-mãe, através e graças a uma equivalência que ele mesmo inventou - a famosa equação pênis=filho, que supostamente possibilitaria a compensação da inveja fálica (Freud, 1924; 1925; 1933). Com efeito, a passagem do masculino/castrado que caracterizava a fase anterior para o masculino/ feminino foi explicada através da invocação do argumento essencialista da castração feminina: o feminino, o feminino "por excelência", vem da castração no sentido anatômico, isto é, no sentido da ausência de pênis; o "fator específico" que explica a separação da mãe, no caso da menina, é a castração; "a diferença anatômica tinha que expressar-se em conseqüências psíquicas" (Freud, 1933, p. 3.171-3.174). Em 1924, Freud afirmou que o feminino era destino e não origem; e, em 1933, que era impossível que a diferença anatômica entre os sexos não tivesse conseqüências psíquicas. Dois enunciados antagônicos, que revelavam a complexidade do tema que estamos tratando (porque o que está em jogo não é a diferença em si, mas a questão da maternidade), mais que as contradições e/ou ambigüidades do próprio Freud.

Como homem de sua época, ele também queria encontrar argumentos no corpo que justificassem a idéia de que o único destino ou o destino "normal" para a mulher era a maternidade, a procriação dentro dos padrões instituídos pelo ideal de família burguesa dominante. A mudança de zona erógena postulada como exigência para tornar-se mulher aparece como mais um argumento que, como observa Laqueur (1990, p. 280), também confirmaria a necessidade de controlar a sexualidade feminina, garantir a continuidade da espécie e o desenvolvimento da civilização; mas, em relação a esta questão, considero importante acrescentar que Freud, à diferença dos médicos da época, que queriam demonstrar através de argumentos biológicos o caráter inato da passividade sexual feminina, não eliminou o prazer da vida 
feminina. Ele (Freud, 1905) transferiu o prazer sexual de uma zona à outra - do clitóris à vagina - e isto, é claro, é questionável, na medida em que supõe a eliminação de uma modalidade de gozo, mas ele não eliminou o prazer da vida da mulher.

A construção freudiana sobre diferença sexual é essencialista, mas, como acabamos de ver através do significado conferido à sexualidade feminina, ela não pode ser identificada com a construção do discurso iluminista. Avancemos um pouco mais, então, para ver outro elemento decisivo (devido às conseqüências que derivam dele) que acrescenta a psicanálise em relação ao discurso dominante na época. No interior da lógica fálica, onde o feminino é definido a partir da maternidade e a maternidade é definida a partir da equivalência simbólica pênis=filho, os três personagens da família edípica entram em cena ocupando um lugar já preestabelecido. O filho figura inevitavelmente como salvador da mãe, ou melhor, como salvador da mulher, pois, graças a ele, ela deixa de ser vista como um ser inexistente ou como um menos-macho, para atingir finalmente o estatuto de ser-mulher. A mãe é identificada com um excesso de desejo dirigido ao filho-salvador, que creio ser bastante "lógico" dentro dessa "lógica", ou seja, que em realidade não faz parte de nenhuma suposta essência ou natureza materna ou feminina, mas é conseqüência de uma determinada construção histórica. Finalmente, o terceiro personagem que completa o triângulo edípico - o pai - é fixado na função de agente do corte, de lei; sua função é separar, ainda quando o preço a pagar seja separar-se dele mesmo, de seu lado desejante, amoroso, vulnerável (Enriquez, 1983, p. 275; Tubert, 1991; Schneider, 2000).

Com essa descrição da família edípica, algo fundamental - que precisa ser destacado, trabalhado e sobretudo questionado - muda em relação à ideologia maternal construída a partir das Luzes. O essencialismo continua sempre presente; aliás, ele é a base onde se apóia esta concepção fálica da maternidade, mas a figura materna que, como vimos, naquela época figurava como símbolo do bem e representante da moral - ou seja, como a própria encarnação da lei, ao menos no interior do espaço familiar -, neste discurso psicanalítico, passa a ser associada à imagem de um excesso, visto sobretudo como ameaça, como fonte de perigo, e que, justamente por esse motivo, pede a presença de um pai-separador, interditor. Os papéis e lugares são invertidos: a mãe não é mais a mulher "por natureza" calma e tranqüila (em outras palavras, passiva ou impassível sexualmente, como diz Laqueur), que sabe, com um saber "quase instintivo", educar os filhos; ela é - de novo "por natureza" - um ser voraz, apaixonado, que representa uma ameaça e que, 
justamente por isso, precisa ser vigiada e controlada por um agente externo, representado agora pelo pai.

Em vez de se perguntar o que acontecia com as mulheres naquela época, quando eram obrigadas a canalizar todo seu erotismo na maternidade, pois os outros modos de expressão eram reprimidos por uma educação que invocava argumentos naturalistas, a psicanálise constrói a idéia de que "toda" mulher deseja ser mãe e a idéia de um amor materno possessivo, definido como excessivo e asfixiante - com um sentido contrário àquele que tinha na época. Para poder desconstruir essa concepção, é importante, por um lado, abandonar o essencialismo reivindicado pela psicanálise para dar conta da diferença entre os $\operatorname{sexos}^{5}$, pois é daí que surge, como uma conseqüência direta, a concepção fálica da maternidade e, por outro lado, é necessário contextualizar, ou seja, tentar entender o que, de fato, acontecia com as mulheres naquela época. Como a mulher não se agarraria "excessivamente" (para o bem e para o mal) ao filho, se é ele quem a faz existir? Isto é, se o contexto histórico e social onde ela nasce, cresce e vive, diz que se não é mãe, ela não é ninguém? A formulação destas questões ajuda a entender melhor o suposto "excesso" materno, embora creio não ser suficiente, que algo na maternidade se mantém como enigma, que talvez esteja relacionado com o próprio desejo - desejo do outro, da diferença - e também com o fato, ao menos até hoje inquestionável, de que o filho se forma no interior do corpo materno.

Retomemos a teoria freudiana sobre diferença sexual. Ao abandonar a problematização do essencialismo e acabar recorrendo ao argumento da anatomia para explicar essa diferença, tal teoria não poderia finalizar de outro modo: sua conseqüência, em relação à maternidade, é que "todas" as mulheres desejam ser mães e que "todas" as mães amam seus filhos com um amor asfixiante. Este é um dos problemas intrínsecos a este modo de pensar a maternidade a partir da lógica fálica - fixar o desejo e o amor maternos num lugar negativizado, na medida em que é assimilado à idéia de excesso, entendida como algo perigoso e não como fonte de vida e de erotismo. Como se fosse necessário substituir o mito do amor materno, criado pela ideologia dominante sobretudo no século XIX, por outro mito igualmente questionável inventado pela psicanálise, onde o maternal é reduzido a uma dimensão que insiste na imagem da mãe devoradora. Em ambos os casos, o que está em jogo e precisa ser desconstruído é o mesmo: a utilização de argumentos essencialistas para unificar o sexo feminino, seja enaltecendo-o, através da imagem idílica de maternidade dominante no sé- 
culo XIX, seja negativizando-o, através da nova imagem de mãe introduzida pela psicanálise.

É importante e necessário desconstruir esse modelo, sobretudo se pensamos na clínica, onde às vezes nos confrontamos com uma ausência e não com um excesso de desejo materno - ou com um excesso de abandono e indiferença, que seria outro modo de dizer a mesma coisa. Neste sentido, Schneider afirma que o objetivo da teoria psicanalítica sobre a diferença entre os sexos pode ser silenciar, mais que refletir, o que acontece com as mulheres, ao menos com algumas delas. Ao comparar alguns sonhos de mulheres relatados por Freud com os textos teóricos onde constrói uma teoria sobre a diferença entre os sexos, a autora encontra uma ausência de eco entre esses sonhos e a teoria que a leva a pensar que o objetivo da teoria pode ser um esforço para não escutar uma palavra feminina inquietante demais, que fragiliza a representação de um excesso de desejo dirigido ao filho. Como se diante de um vazio que ameaça, porque não pode ser controlado, o melhor fosse construir a idéia de um excesso que justifica, per se, a necessidade de incorporar um agente externo controlador. A experiência clínica está aí, presente, mostrando que muitas vezes não estamos diante de um "excesso", mas de uma "deficiência" de desejo materno, e que, nestes casos, o problema não é como separar-se de uma mãe asfixiante, mas como construir um começo possível, como fazer existir o que nunca existiu. Que significa isto? Significa que o problema das mães às vezes não é a falta de pênis, mas a falta de desejo, e que é justamente para se proteger desse perigo que se inventa o fantasma da captura materna (Schneider, 1992).

\section{As mães têm os filhos sozinhas}

Em relação ao terceiro postulado levantado, quando comecei a trabalhar o tema da maternidade a partir da psicanálise - a idéia de que as mães têm os filhos sozinhas - cuja origem em realidade remonta a um tempo anterior à instauração do patriarcado no Ocidente, acompanho a interpretação de Schneider, a partir da análise de três textos de Freud: a carta-poema escrita por Freud a Fliess, por ocasião do nascimento de seu filho; o ensaio dedicado a Moisés e "Teorias sexuais infantis" (Schneider, 2000).

Na carta-poema (1899) e em Moisés (1939) - ou seja, dois escritos bem separados no tempo -, a paternidade aparece necessitando uma instância superior para ser reconhecida e a maternidade como não precisando ser demonstrada, porque pertence ao mundo do sensorial, ou seja, aquilo que se manifesta através dos sentidos. Isso significa, para Freud, que o pai é supe- 
rior, mas necessita ao mesmo tempo da intervenção de um trabalho de pensamento para ser reconhecido, o que, segundo Schneider (2000, p. 57), levaria inevitavelmente a pensar que o filho seria só da mãe, atribuível só a ela. A negação do encontro entre o homem e a mulher para haver fecundação, invocada com força e sem sutileza em alguns dos mitos analisados (de autoctonia, de Atena e Zeus, de Pandora), permanece como fantasma nesses dois textos, fixando o pai na função do homem capaz de "conter, de canalizar a potência do sexo feminino" para que obedeça à lei (como escreve Freud na carta a Fliess ${ }^{6}$ ), e confirmando o velho argumento da partenogênese feminina, que, no caso da psicanálise, identifica mulher com natureza entendida como um registro que se opõe à cultura ${ }^{7}$. O pai desejante, que participa desde as origens da gestação, está ausente nos dois textos, onde aparece só num tempo posterior, como agente do corte.

O artigo "Teorias sexuais infantis" (1908) é importante neste sentido, porque num primeiro momento, antes da construção da primeira teoria sexual infantil, sugeria um movimento que teria permitido um modo diferente de entender essas questões ${ }^{8}$. Vejamos: ao descrever a reação da criança diante da gravidez materna, Freud dizia que, de fato, ela tinha conseguido descobrir sozinha que o filho se forma no interior do corpo da mãe e que, justamente no momento em que se encontrava no melhor caminho para descobrir a participação do pai na fecundação (por causa, inclusive, do que acontecia em seu próprio corpo nesse momento de seu desenvolvimento), interrompeu sua investigação para construir a teoria de que a mãe tem um órgão igual ao dele. O menino "tropeça" na teoria, dizia Freud, mas em realidade é ele mesmo quem a construiu para negar algo que havia começado a descobrir - o encontro sexuado, que poderia reenviá-lo a uma outra imagem de pai e de mãe, onde o primeiro poderia expressar-se em seu lado fecundador e a mãe poderia ser vista fora da alternativa castrada - nãocastrada. A primeira teoria sexual infantil é, então, uma teoria construída pelo menino, que acaba confirmando a tese do monismo fálico, só que através de um argumento que diz respeito à questão das origens da vida: como (a criança) entrou aí, no corpo materno? Quando essa teoria surge, ela fecha a possibilidade de um modo novo de pensar estas questões, que reclama a incorporação da dimensão do desejo, de diferença e de alteridade. Em vez de favorecer o encontro com a diferença (neste caso, diferença de sexos, considerada, ao menos até agora, necessária para haver fecundação), a teoria da mãe fálica opõe os sexos, deixando as mães sozinhas com os 
filhos e identificadas com a natureza, e os pais fixados na identidade de representantes da cultura. No século XIX, se descobre que a fecundação supõe o "encontro" do espermatozóide e do óvulo; porém, as teorias continuam - inclusive a teoria psicanalítica, ao menos em sua versão fálica negando esse encontro.

Antes de finalizar, destaco dois pontos. Em primeiro lugar, que o objetivo deste trabalho foi refletir sobre a concepção fálica de maternidade construída por Freud em alguns de seus textos, levantando algumas questões que possibilitaram seu questionamento. Mas que, é importante destacar que em outros textos, que aqui não analisamos, o próprio Freud introduziu novos elementos que permitiam sustentar ou abrir outros caminhos para leituras alternativas sobre o tema. Com efeito, se pensamos, como destaca Birman (1997), que a vida vem de fora e não de dentro, ou seja, que é através do outro que nos constituímos, a maternidade pode ser vista como experiência de alteridade e o excesso materno como fonte de estímulo e de vida, o que não significa negar a dimensão de conflito que faz parte do humano ${ }^{9}$.

Em segundo lugar, gostaria de finalizar este trabalho, invocando a idéia de enigma, a qual Freud recorreu tantas vezes quando pensou a questão do feminino, e invocá-la através do mesmo sentido que ele lhe atribuiu, ou seja, como "limite" na compreensão do feminino e não como uma identidade feminina enigmática (Freud, 1933). Considero importante manter esta idéia e ao mesmo tempo estendê-la a um pensamento sobre a diferença entre os sexos, no que diz respeito à mulher, mas também ao homem; à maternidade, mas também à paternidade e, em definitivo, à própria idéia de diferença entre os sexos, aberta sempre a novas interpretações. Se há enigma, ele está nos homens, nas mulheres ou, como diz Birman, na própria diferença entre os sexos. As teorias, as tentativas de sistematizar esta diferença, são fálicas; podem ser construídas por homens ou por mulheres; pode ser o masculino ou o feminino o elemento valorizado, mas, em ambos casos, o problema é mantido porque se pretende encontrar argumentos específicos para dar corpo a uma identidade masculina ou feminina que acaba unificando e deixando de lado a singularidade de cada percurso (Birman, 1996). Deixemos então a "diferença" como enigma, o que não significa que deixaremos de refletir sobre essas questões, que estarão sempre perturbando e estimulando nosso pensamento. 


\section{Notas}

1 Psicanalista, doutora em Saúde Coletiva pelo Instituto de Medicina Social da UERJ.

2 A esse respeito, ver Neri (1999).

3 A esse respeito, ver Arán (1977).

4 Para uma abordagem mais aprofundada dessa temática e seus desdobramentos atuais, ver Birman (1996).

5 A esse respeito, ver Nunes (2000).

6 Schur. La mort dans la vie de Freud (citado por Schneider, 2000, p. 56).

7 É importante observar que a suposta crença na partenogênese feminina em psicanálise, que estaria por trás da imagem da mãe fálica, adquire um significado diferente daquele que tinha no tempo anterior à instauração do patriarcado, onde, como observa Badinter (1986), a fertilidade feminina ligada à natureza tinha um valor cultural, ou seja, onde a natureza não era entendida como o oposto da cultura.

8 Cabe salientar aqui que a concepção fálica de maternidade e paternidade, presente em Freud, foi retomada de um modo mais radical

- porque mais sistemático

- por Lacan.

9 Em minha tese de doutorado, desenvolvo esta idéia, a partir de alguns textos de Freud que permitem pensar a maternidade fora da lógica fálica, como uma experiência que poderíamos chamar de alteridade.

\section{Referências Bibliográficas}

ARÁN, M. A diferença como singularidade: sobre a questão da feminilidade na obra freudiana. Rio de Janeiro: IMS/UERJ, 1997 (Série Estudos em Saúde Coletiva, 156).

BADINTER, E. L'amour en plus. Paris: Flammarion, 1980. . Um é o outro. Rio de Janeiro: Nova Fronteira, 1986.

BERRIOT-SALVADORE, E. O discurso da medicina e da ciência. In: DUBY e PERROT (dir.). História das mulheres em Ocidente - séc. XIX. Porto: Afrontamento, 1994.

BIRMAN, J. Cartografías do feminino. São Paulo: Editora 34, 1999. 34, 1997. Estilo e modernidade em psicanálise. São Paulo: Editora

- Por uma estilística da existência: sobre a psicanálise, a modernidade e a arte. São Paulo: Editora 34, 1996.

BROWN, P. Antiguidade tardia. In: ARIES e DUBY (dir.). História da vida privada - I. São Paulo: Cia. das Letras, 1992.

CHAUÍ, M. Repressão sexual, essa nossa (des)conhecida. São Paulo: Brasiliense, 1984. 
ENRIQUEZ, E. De la horde à l'Etat. Paris: Gallimard, 1983.

FRAISSE, G., PERROT, M. Introdução: ordens e liberdade. In: DUBY e PERROT (dir.). História das mulheres em Ocidente - séc. XIX. Porto: Afrontamento, 1994.

FRAISSE, G. Les femmes et leur histoire. Paris: Gallimard, 1998.

FREUD, S. Algunas consecuencias psíquicas de la diferencia anatómica entre los sexos (1925). In: Obras Completas. Madrid: Biblioteca Nueva, 1973.

La disolución del Complejo de Edipo (1924). In: Obras

completas. Madrid: Biblioteca Nueva, 1973. La femineidad (1933).In: Obras completas. Madrid: Bibliote-

ca Nueva, 1973. Moisés y la religión monoteista (1939). In: Obras completas.

Madrid: Biblioteca Nueva, 1973. Organización genital infantil (1923). In: Obras completas.

Madrid: Biblioteca Nueva, 1973. Sobre la sexualidad femenina (1931). In: Obras completas.

Madrid: Biblioteca Nueva, 1973. . Teorias sexuales infantiles (1908). In: Obras completas.

Madrid: Biblioteca Nueva, 1973.

. Tres ensayos para una teoria sexual (1905). In: Obras

completas. Madrid: Biblioteca Nueva, 1973.

HÉRITIER, F. Masculin/féminin. La pensée de la différence. Paris: Odile Jacob, 1996.

KNIBIEHLER, Y. Corpos e corações. In: DUBY e PERROT (dir.). História das mulheres em Ocidente - séc. XIX. Porto: Afrontamento, 1994.

LAQUEUR, T. La fabrique du sexe. Paris: Gallimard, 1990.

LORAUX, N. Les enfants d'Atenas. Idées athéniennes sur la citoyenneté et la division des sexes. Paris: Seuil, 1990.

NERI, R. Modernidade: encontro histórico da psicanálise com a histeria. Tese (Doutorado em Psiquiatria) - Instituto de Psiquiatria, Universidade Federal do Rio de Janeiro, 1999.

NUNES, S. O corpo do diabo entre a cruz e a caldeirinha. Rio de Janeiro: Civilização Brasileira, 2000.

SCHNEIDER, M. La part de l'ombre. Paris: Aubier, 1992. Genéalogie du masculin. Paris: Aubier, 2000.

SENNETT, R. Carne e pedra. Rio de Janeiro: Record, 1997. 
SISSA, G. Filosofias del género: Platón, Aristóteles y la diferencia sexual. Historia de las mujeres, I, Madrid: Taurus, 1993.

TUBERT, S. Mujeres sin sombra. Maternidad y tecnologia. Madrid: Siglo XXI, 1991.

\section{ABSTRACT}

Maternity as an enigma. Athens, the Enlightenment and Freud

This work examines maternity from a historical point of view. I look into the discursive constructions which dominated the Classical Greece and the Enlightenment, analyzing Freud's specific texts. The main objective is to demonstrate the importance of the patriarchal tradition, which comes from Antiquity, on the phallic representation of maternity in Freud (although other interpretations are also possible). Three fundamental pillars sustain this tradition: the phallic monism, the essentialism in understanding the difference between sexes and the idea that mothers have children without the father's interference.

Keywords: Maternity; phallic representantion; history; psychoanalysis.

\section{RÉSUMÉ}

Maternité comme énigme. Athènes, les Lumières et Freud.

Ce travail examine la question de la maternité à partir d'une démarche historique des constructions discoursives dominantes en Grèce et du siècle des Lumières, et de l'analyse de certains textes de Freud. L'objectif principal c'est d'essayer de montrer le poids d'une tradition patriarchale qui remonte à l'Antiquité, sur la réprésentation phallique de la maternité en Freud (malgré l'ouverture aussi d'autres voies interprétatives alternatives), appuyée sur trois piliers fondamentaux: le monisme phallique; l'essentialisme présent dans l'entendement de la question de la différence des sexes; et l'idée que les mères ont seules les fils, sans l'intervention du père.

Mots-clés: Maternité; représentation phallique; histoire; psychanalyse.

Recebido em 29/09/00.

Aprovado em 23/10/00. 